\title{
PENGARUH PEMBERIAN KOMPENSASI TERHADAP PENINGKATAN KINERJA GURU HONORER
}

\author{
${ }^{1}$ Maharani, ${ }^{2}$ Zakaria, ${ }^{3}$ Muh.Rasmi \\ ${ }^{1}$ Manajemen Pendidikan Islam IAIN Bone, Jl. HOS.Cokroaminoto Watampone, Indonesia \\ e-mail: maharanirani0967@gmail.com \\ ${ }^{2,3}$ Pascasarjana IAIN Bone, Jl. HOS.Cokroaminoto Watampone, Indonesia \\ e-mail: zakaria28041970@gmail.com \\ e-mail: muhrasmielnoer@gmail.com
}

\begin{abstract}
The main problem in this research is 1) How to provide compensation in MA Al-IhsanKajuara Awangpone District Bone Regency. 2) How is the performance of the honorary teacher in MA AlIhsan Kajuara Awangpone District Bone Regency. 3) How is the effect of giving compensation to the improvement of the performance of honorary teachers in MA Al-Ihsan Kajuara Awangpone District Bone Regency. The research method used is descriptive quantitative research and population in this study were all honorary teachers who tought the at the school with a sample of 16 honorary teachers. Research instruments using questionnaires and documentation. The data analysis technique used is descriptive analysis with the product moment statistical test. Based on the results of data analysis using descriptive statistics, it is known that the average value for compensation $(X)$ is 16, number 16 is in the sufficient category and the average value for the performance of honorary teachers $(Y)$ is 52,25 , number 52,25 is in the good category. While the results of the statistical analysis of the product moment show the regression test results obtained bythe value of $r_{x y}=0,685$, this proves that the provision of compensation for the performance of honorary teachers is relatively strong. Then used the $F$ statistic with the criteria for rejecting $t e s t H_{0}$ if $F_{\text {count }}>F_{\text {table }}$ with a value 12,36>4,60. This shows that there is a positive and significant effect between the provision of compensation to the improvement of the performance of honorary teachers in MA Al-Ihsan Kajuara Awangpone District Bone Regency.
\end{abstract}

Keywords: Compensation and Performance Honorary Teacher

\section{PENDAHULUAN}

Dalam sebuah lembaga pendidikan guru memiliki peran dan kedudukan yang sangat penting. Berkenaan dengan lembaga pendidikan, guru merupakan tenaga pendidik yang mempunyai tugas pokok dan fungsi untuk meningkatkan mutu pendidikan, agar dapat menjalankan tugas dan fungsinya secara maksimal maka seorang guru diharapkan memiliki kinerja yang tinggi terhadap pekerjaannya.

Tinggi rendahnya kinerja guru berkaitan erat dengan sistem pemberian kompensasi yang ditetapkan oleh madrasah.Pemberian kompensasi yang tidak tepat berpengaruh terhadap peningkatan kinerja guru. Ketidaktepatan pemberian kompensasi disebabkan oleh pemberian jenis kompensasi yang kurang menarik dan pemberian penghargaan yang kurang tepat. 
Kompensasi merupakan salah satu faktor penting dan menjadi perhatian penuh pada madrasah dalam mempertahankan guru yang berkualitas. Berbagai madrasah berkompetisi untuk memperoleh guru yang berkualitas, karena kualitas hasil pekerjaan ditentukan oleh kompetensi yang dimiliki oleh guru.

Sistem kompensasi yang baik mampu memberikan kepuasan bagi guru yang memungkinkan madrasah memperoleh, mempekerjakan, dan mempertahankan gurunya.Semua guru berhak mendapatkan penghasilan yang baik, tidak terkecuali guru honorer yaitu berupa gaji dan tunjangan. Dalam UUD RI No.14 Tahun 2005 Tentang Guru dan Dosen pasal 14 menyatakan bahwa semua guru berhak memperoleh penghasilan yang layak di atas kebutuhan hidup minimum dan jaminan kesejahteraan sosial. ${ }^{1}$

\section{Kompensasi}

\section{Pengertian Kompensasi}

Kompensasi merupakan suatu bentuk biaya yang harus dikeluarkan oleh madrasahdengan harapan bahwa madrasah akan memperoleh imbalan dalam bentuk prestasi kerja dari guru.Kompensasi merupakan suatu balas jasa atau imbalan yang diberikan madrasah kepada guru atas pekerjaan mereka. ${ }^{2}$

\section{Jenis-Jenis Kompensasi}

a. Gaji adalah balas jasa dalam bentuk uang yang diterima guru sebagai konsekuensi dari kedudukannya sebagai seorang guru yang memberikan sumbangan tenaga dan pikiran dalam mencapai tujuan madrasah.

b. Insentif merupakan imbalan langsung yang dibayarkan kepada guru karena kinerjanya melebihi standar yang ditentukan.

c. Fasilitas, misalnya ruang kantor dan tempat parkir. ${ }^{3}$

\footnotetext{
${ }^{1}$ Departemen Agama RI, Al-Qur'an Al Karim dan Terjemahnya (Jakarta: CV. Toha Putra, 1996), h. 162.

${ }^{2}$ Herman Sofyandi, Manajemen Sumber Daya Manusia (Cet. I; Yogyakarta: Graha Ilmu, 2008), h. 159.

${ }^{3}$ Rivai, Pengaruh Kompensasi, Lingkungan Kerja dan Motivasi Kerja Terhadap Kinerja Guru Tidak Tetap (Skripsi, Semarang, 2010), h. 27.
} 


\section{Kinerja Guru Honorer \\ Pengertian Kinerja Guru Honorer}

Kinerja merupakan prestasi yang dicapai oleh seseorang dalam melaksanakan tugas atau pekerjaannya selama periode tertentu sesuai standar dan kriteria yang telah ditetapkan untuk pekerjaan tersebut. ${ }^{4}$

Guru menurut bahasa adalah orang yang pekerjaannya (mata pencahariannya, profesinya) mengajar. Sedangkan menurut istilah guru adalah orang yang sebagai pendidik ataupun pengajar yang merupakan faktor penentu kesuksesan setiap usaha pendidikan.Guru juga diartikan sebagai sosok yang rela mencurahkan sebagian besar waktunya untuk mengajar dan terhormat di masyarakat. ${ }^{5}$

Honor dalam Kamus Besar Bahasa Indoenesia artinya upah sebagai imbalan jasa (yang diberikan kepada pengarang, penerjemah, dokter, pengacara, konsultan dan tenaga honorer). Honor juga berarti upah di luar gaji. Tenaga honorer dalam hal ini guru honorer sesuai asumsi umum adalah tenaga kerja atau guru yang bekerja disuatu instansi pemerintah atau swasta tanpa diberikan gaji kepadanya dan pendapatannya hanyalah berasal dari kebijakan atasan yang mengangkatnya. ${ }^{6}$

Guru honorer adalah guru yang memiliki hak untuk memperoleh honorarium, baik perbulan maupun pertriwulan, mendapatkan perlindungan hukum dan cuti.Guru honorer merupakan guru yang diangkat secara resmi oleh pemerintah untuk mengatasi kekurangan guru. $^{7}$

Kinerja guru honorer dapat diartikan sebagai hasil kerja berdasarkan penilaian tentang tugas dan fungsi jabatan sebagai pendidik, manajer lembaga pendidikan, administrasi, supervisor, inovator dan motivator atau apapun yang penilaiannya dilaksanakan oleh suatu madrasah. ${ }^{8}$

${ }^{4}$ Muhammad Ilyas Ismail, Guru Sebuah Identitas (Cet. I;Makassar: Alauddin University Press, 2013), h. 67.

${ }^{5}$ Muhibbin Syah, Psikologi Pendidikan dengan Pendekatan Baru (Cet. I; Bandung: PT Remaja Rosdakarya, 1995), h. 223.

${ }^{6}$ Tim PenyusunPusat dan Pengembangan Bahasa, Kamus Besar Bahasa Indonesia(Jakarta: Balai Pustaka, 1989) h.970.

${ }^{7}$ E Mulyasa, Menjadi Guru Profesional (Bandung: PT Remaja Rosdakarya, 2006), h. 20.

${ }^{8}$ Abdullah Munir, Menjadi Kepala Sekolah Efektif (Cet. I; Yogyaakarta: Ar-Ruzz Media, 2008), h. $31-32$. 


\section{Penilaian Kinerja Guru Honorer}

Penilaian kinerja guru honorer adalah suatu upaya untuk memperoleh gambaran tentang pengetahuan, keterampilan, nilai dan sikap guru dalam melaksanakan tugas dan fungsinya yang ditunjukkan dalam perbuatan, penampilan dan prestasi kerjanya. Kinerja guru honorer tidak hanya ditunjukkan oleh hasil kerja, akan tetapi juga oleh perilaku dalam bekerja. Kinerja guru honorer juga dapat ditunjukkan dari seberapa besar kompetensikompetensi yang dipersyaratkan dipenuhi. ${ }^{9}$ Kompetensi tersebut meliputi:

a. Kompetensi Pedagogik meliputi pemahaman guru terhadap siswa, perancangan dan pelaksanaan pembelajaran, evaluasi hasil belajar dan pengembangan siswa untuk mengaktualisasikan berbagai potensi yang dimilikinya.

b. Kompetensi Kepribadian adalah kemampuan guru secara personal yang tercermin pada kepribadian yang mantap, stabil, dewasa, arif, berwibawa, menjadi teladan siswa dan berakhlak mulia.

c. Kompetensi Profesional merupakan penguasaan materi pembelajaran secara luas dan mendalam, yang mencakup penguasaan materi kurikulum mata pelajaran di madrasah dan substansi keilmuan yang mencakup materinya, serta penguasaan terhadap struktur dan metodologi keilmuannya.

d. Kompetensi Sosial merupakan kemampuan guru untuk berkomunikasi secara efektif dengan siswa, sesama pendidik, tenaga kependidikan, orangtua/wali siswa dan masyarakat sekitar. ${ }^{10}$

\section{METODE}

Jenis penelitian yang penulis gunakan dalam penelitian ini adalah penelitian kuantitatif. Penelitian ini berlangsung di MA Al-Ihsan Kajuara yang merupakan lembaga pendidikan formal tingkat menengah atas yang terletak di Jl. Mesjid Desa Carigading Kajuara Kecamatan Awangpone Kabupaten Bone Provinsi Sulawesi Selatan.

Populasi dalam penelitian ini yakni seluruh guru honorer yang terdiri dari 16 orang di MA Al-Ihsan Kajuara Kecamatan Awangpone Kabupaten Bone.Sampel dalam penelitian ini yakni jumlah keseluruhan populasi. h. 88 .

${ }^{9}$ E Mulyasa, Uji Kompetensi dan Penilaian Kinerja Guru (Bandung: PT Remaja Rosdakarya, 2013),

${ }^{10}$ Supardi, Sekolah Efektif, Konsep Dasar dan Praktiknya(Cet. I; Jakarta: Rajawali Pers, 2013),h.105. 
Instrumen Penelitian yang digunakan adalah sebagai berikut :

a. Pedoman observasi yang digunakan dalam penelitian ini berupa catatan mengenai data pemberian kompensasi dan kinerja guru honorer.

b. Daftar kuesioner yang digunakan berkaitan dengan daftar pernyataan variabel pemberian kompensasi dan kinerja guru honorer.

c. Dokumen yang digunakan yaitu berupa daftar riwayat hidup dan daftar gaji pertriwulan guru honorer.

Adapun teknik pengumpulan datanya yaitu :

a. Observasi yaitu melakukan pengamatan secara langsung untuk melihat sistem pemberian kompensasi dan kinerja guru honorer.

b. Kuesioner/Angket yaitu teknik pengumpulan data dengan memberikan daftar pernyataan kepada responden mengenai pemberian kompensasi yang terdiri dari 5 pernyataan dan kinerja guru honorer yang terdiri dari 15 pernyataan.

c. Dokumentasi yaitu teknik pengumpulan data yang berupa daftar riwayat hidup dan daftar gaji pertriwulan guru honorer serta foto untuk melengkapi dokumen.

Data pemberian kompensasi dan kinerja guru honorer menggunakan data analysis descriptive statistics pada microsoft excel 2010.

\section{HASIL DAN PEMBAHASAN}

\section{Kompensasi}

Pemberian kompensasi dapat diketahui berdasarkan hasil analisis angket yang disebar kepada guru honorer di MA Al-Ihsan Kajuara yang berjumlah 16 orang.Dalam Angket tersebut terdiri dari 5 pernyataan mengenai pemberian kompensasi.

Berdasarkan data yang diperoleh dari hasil angket pemberian kompensasi yang telah dikumpulkan, ditunjukkan pada tabel 1:

Tabel 1.Nilai Variabel Pemberian Kompensasi (X)

\begin{tabular}{|l|c|}
\hline \multicolumn{2}{|c|}{ Column 1 } \\
\hline Mean & 16 \\
\hline Median & 16 \\
\hline Mode & 16 \\
\hline Standard Deviation & 1,236595 \\
\hline Sample Variance & 1,529167 \\
\hline Range & 4 \\
\hline
\end{tabular}




\begin{tabular}{|l|c|}
\hline \multicolumn{2}{|c|}{ Column 1 } \\
\hline Minimum & 14 \\
\hline Maximum & 18 \\
\hline Sum & 255 \\
\hline Count & 16 \\
\hline
\end{tabular}

Berdasarkan tabel 1, data menunjukkan bahwa nilai mean dari variabel pemberian kompensasi (X) adalah 16, maka dapat dibuatkan tabel nilai interval sebagai berikut:

Tabel 2.Nilai Interval Kategori Pemberian Kompensasi

\begin{tabular}{|c|c|c|c|c|}
\hline No & Kategori & Interval Skor & Frekuensi & Persentase \\
\hline 1 & Tidak Baik & $14-15$ & 2 & $12,5 \%$ \\
\hline $\mathbf{2}$ & Cukup & $\mathbf{1 6}-\mathbf{1 7}$ & $\mathbf{9}$ & $\mathbf{5 6 , 2 5 \%}$ \\
\hline 3 & Baik & $18-19$ & 5 & $31,25 \%$ \\
\hline 4 & Sangat Baik & $20-21$ & 0 & $0 \%$ \\
\hline
\end{tabular}

Berdasarkan tabel2, menunjukkan bahwa angka 16 berada pada kategori cukup yaitu terletak pada interval antara 16-17, dengan demikian data menunjukkan bahwa pemberian kompensasi di MA-Al Ihsan Kajuara Kecamatan Awangpone Kabupaten Bone termasuk dalam kategori cukup.

\section{Kinerja Guru Honorer}

Kinerja guru honorer di MA Al-Ihasan Kajuara dapat diketahui berdasarkan hasil analisis angket yang disebar kepada guru honorer di madrasah tersebut yang berjumlah 16 orang. Dalam Angket tersebut, terdiri dari 15 pernyataan mengenai kinerja guru honorer yang terkait dengan kompetensi paedagogik, kompetensi kepribadian, kompetensi profesional dan kompetensi sosial yang menandakan kinerja yang dirasakan oleh guru honorer di madrasah tersebut.

Berdasarkan data yang diperoleh dari hasil angket kinerja guru honorer yang telah dikumpulkan, dapat ditunjukkan pada tabel 3:

Tabel 3.Nilai Variabel Kinerja Guru Honorer (Y)

\begin{tabular}{|l|c|}
\hline \multicolumn{2}{|c|}{ Column 2 } \\
\hline Mean & 52,25 \\
\hline Median & 54,5 \\
\hline Mode & 45 \\
\hline Standard Deviation & 5,372771 \\
\hline Sample Variance & 28,86667 \\
\hline Range & 15 \\
\hline Minimum & 45 \\
\hline
\end{tabular}




\begin{tabular}{|l|c|}
\hline Maximum & 60 \\
\hline Sum & 836 \\
\hline Count & 16 \\
\hline
\end{tabular}

Berdasarkan tabel 3, data menunjukkan bahwa nilai mean dari variabel kinerja guru honorer (Y) adalah 52,25, maka dapat dibuatkan tabel nilai interval sebagai berikut:

Tabel 4.Nilai Interval Kategori Kinerja Guru Honorer

\begin{tabular}{|c|c|c|c|c|}
\hline No & Kategori & Interval Skor & Frekuensi & Persentase \\
\hline 1 & Tidak Baik & $45-48$ & 5 & $31,25 \%$ \\
\hline 2 & Cukup & $49-51$ & 2 & $12,5 \%$ \\
\hline 3 & Baik & $52-56$ & 5 & $31,25 \%$ \\
\hline 4 & Sangat Baik & $57-60$ & 4 & $25 \%$ \\
\hline
\end{tabular}

Berdasarkan tabel 4, menunjukkan bahwaangka 52,25 berada pada kategori baik yaitu terletak pada interval antara 52-56. Dengan demikian, data menunjukkan bahwa kinerja guru honorer di MA Al-Ihsan Kajuara Kecamatan Awangpone Kabupaten Bone termasuk dalam kategori baik.

\section{Pengaruh Pemberian Kompensasi Terhadap Peningkatan Kinerja Guru Honorer}

Untuk mengetahui pengaruh pemberian kompensasi (X) terhadap kinerja guru honorer (Y) di MA Al-Ihsan Kajuara, dapat dilihat pada gambar berikut: 


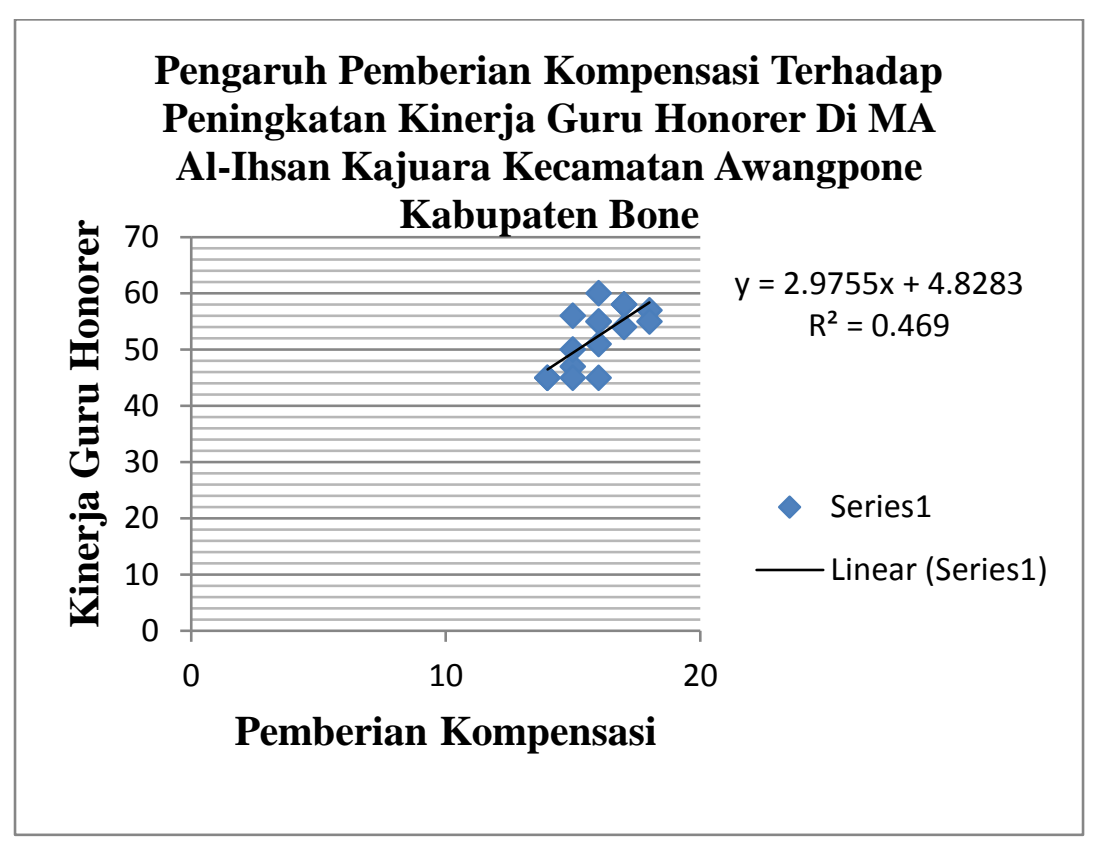

\section{Gambar 1.Grafik Regresi Linear Pengaruh Pemberian Kompensasi Terhadap Peningkatan Kinerja Guru Honorer}

Berdasarkan pada gambar 1 persamaan garis regresi dapat diartikan bahwa konstanta (a) sebesar 4,8283 menunjukkan bahwa ketika variabel pemberian kompensasi konstan, maka rata-rata kinerja guru honorer sebesar 4,8283. Dan koefisien regresi pemberian kompensasi(b) sebesar 2,9755 menunjukkan bahwa setiap kenaikan 1 konstanta pada variabel pemberian kompensasi, maka akan meningkatkan kinerja guru honorer sebesar 2,9755. Serta koefisien regresi bernilai positif menunjukkan bahwa semakin baik pemberian kompensasi maka semakin baik pula kinerja guru honorer. Adapun besarnya andil dari variabel $\mathrm{X}$ terhadap naik turunnya variabel $\mathrm{Y}\left(R^{2}\right)$ yaitu 0,469 .

\section{KESIMPULAN}

Berdasarkan hasil analisis pada variabel pemberian kompensasi (X), dapat diketahui bahwa nilai rata-rata untuk variabel pemberian kompensasi (X) adalah 16, berada pada kategori cukup yaitu terletak pada interval 16 - 17. Berarti pemberian kompensasi di MA Al-Ihsan Kajuara telah memenuhi dimensi pemberian kompensasi tetapi masih perlu ditingkatkan.

Berdasarkan hasil analisis pada variabel kinerja guru honorer (Y), dapat diketahui bahwa nilai rata-rata untuk variabel kinerja guru honorer (Y) adalah 52,25, berada pada 
kategori baik yaitu terletak pada interval 52-56. Dengan demikian, bahwa guru honorer di MA Al-Ihsan Kajuara memenuhi kriteria dimensi kinerja guru honorer.

Berdasarkan hasil dari korelasiproduct moment diperoleh nilai $r_{x y}=0,685$, membuktikan bahwa pemberian kompensasi dan kinerja guru honorer tergolong kuat. Kemudian digunakan statistik $\mathrm{F}$ dengan kriteria uji tolak $\mathrm{H}_{0}$ jika $\mathrm{F}_{\text {hitung }}>\mathrm{F}_{\text {tabel }}$ dengan nilai 12,36>4,60. Hal ini menunjukkan bahwa terdapat pengaruh yang positif dan signifikan antara pemberian kompensasi terhadap kinerja guru honorerdi MA Al-Ihsan Kajuara.

\section{SARAN}

Kepada kepala madrasah di MA Al-Ihsan Kajauara diharapkan kedepannya memberikan kompensasi yang baik kepada guru honorer sehingga guru honorer tersebut lebih meningkatkan kinerjanya agar segala aktivitas-aktivitas yang dikerjakan dapat terlaksana dengan baik, karena keberhasilan penyelenggaraan pendidikan ditentukan oleh kinerja guru.

\section{DAFTAR RUJUKAN}

Departemen Agama RI. (2006). Undnag-Undang dan Peraturan Pemerintah RI.Jakarta: Direktorat Jenderal Pendidikan Islam.

Ismail, Muhammad Ilyas. (2013). Guru Sebagai Identitas.Cet. I; Makassar: Alauddin University Press.

Mulyasa, E. (2006). Menjadi Guru Profesional. Bandung: PT Remaja Rosdakarya. .(2013). Uji Kompetensi dan Penilaian Kinerja Guru. Bandung: PT Remaja Rosdakarya..

Munir, Abdullah. (2008). Menjadi Kepala Sekolah Efektif.Cet. I; Yogyakarta: Ar-Ruzz Media.

Rivai.Pengaruh Kompensasi Lingkungan Kerja dan Motivasi Kerja Terhadap Kinerja Guru Tidak Tetap.Skripsi; Semarang, 2010.

Sofyandi, Herman. (2008). Manajemen Sumber Daya Manusia.Cet. I; Yogyakarta: Graha Ilmu.

Supardi.(2013). Sekolah Efektif Konsep Dasar dan Praktiknya.Cet. I; Jakarta: PT Grafindo Persada.

Syah, Muhibbin. Psikologi Pendidikan dengan Pendekatan Baru.Cet. I; Bandung: PT Remaja Rosdakarya, 1995.

Tim Penyusun Pusat dan Pengembangan Bahasa. Kamus Besar Bahasa Indonesia.Jakarta: Balai Pustaka, 1989. 